\title{
Chronic Hypoxemia in the Newborn Lamb: Cardiovascular, Hematopoietic, and Growth Adaptations
}

\author{
DAVID TEITEL, DANIEL SIDI, ${ }^{1}$ DANIEL BERNSTEIN, MICHAEL A. HEYMANN, AND \\ ABRAHAM M. RUDOLPH
}

Cardiovascular Research Institute and the Departments of Pediatrics, Physiology, and Obstetrics, Gynecology and Reproductive Sciences, University of California, San Francisco, California 94143

\begin{abstract}
We have created a model of chronic hypoxemia in the newborn lamb by decreasing pulmonary blood flow in the presence of an atrial septal defect. Via a left lateral thoracotomy, we place an inflatable balloon around the pulmonary artery and perform an atrial septostomy under direct vision. We also insert several vascular catheters and place an electromagnetic flow transducer around the ascending aorta. Three days after surgery, we inflated the balloon in 11 lambs such that arterial oxygen saturation decreased to 60 to $75 \%$. Studies were performed on these lambs twice weekly and weekly on 12 normoxemic lambs. Growth decreased sharply $(47 \pm 123$ versus $221 \pm 82$ g/ day) at the onset of hypoxemia and remained low, although oxygen consumption followed the normal gradual decline. Heart rate remained elevated throughout the study. Arterial $\mathrm{PCO}_{2}$ levels decreased from $40 \pm 5$ to $35 \pm 7$ torr and remained low. Systemic blood flow decreased at balloon inflation but quickly returned to normal. Mixed venous saturation was low, but could decrease further with shivering. Systemic oxygen delivery decreased initially but returned to normal as $\mathrm{Hb}$ concentration rose (from $9.4 \pm$ 1.5 to $12.5 \pm 2.2 \mathrm{~g} / \mathrm{dl}$ ). P50 increased normally over the study period. Four of the 11 hypoxemic lambs died during the study. These data show that, in the chronically hypoxemic newborn, systemic oxygen delivery is maintained primarily by a rising $\mathrm{Hb}$. Total body oxygen consumption is maintained at rest but is redistributed away from anabolic requirements and toward cardiorespiratory work. This signal to decrease growth occurs despite less than maximal oxygen extraction at rest. (Pediatr Res 19: 10041010, 1985)
\end{abstract}

Cyanotic congenital heart disease is the most common cause of chronic hypoxemia in infancy and young childhood. Many forms of cyanotic heart disease are complex and not readily amenable to early surgical correction or alleviation of the hypoxemia. The aberrations of normal function caused by chronic hypoxemia must be understood so that we may attenuate its impact as the patient awaits surgical correction. We therefore

Received January 8, 1985; accepted May 20, 1985.

Address all correspondence and reprint requests to David F. Teitel, M.D., 1315M, University of California, San Francisco, CA 94143.

D.F.T was supported by a research fellowship from the Medical Research Council of Canada during the initial phases of this project and is currently supported by an NIH New Investigator Award (HL 30457). This project was supported in part by an NIH Research Grant (HL 23681) and an NIH Program Project Grant (HL 24056).

1 Present address: Service de Cardiologie Infantile, Hopital Necker-Enfants Malades, Rue Sevres, Paris 75015, France. developed a model of a common cyanotic heart lesion to assess some of its cardiovascular and metabolic effects on the newborn lamb.

Several authors have studied acute hypoxemia in the developing organism and elucidated its effects on general cardiovascular function (1-3), regional blood flow $(1,4,5)$, metabolic activity $(6,7)$, and course of decompensation (1). The effects of sympathetic blockade $(8,9)$ and decreasing $\mathrm{Hb}$ oxygen affinity $(10,11)$ on the response to acute hypoxemia have also been addressed. Few studies have been performed on the chronically hypoxemic developing organism to understand the change from acute to chronic adaptations and the sequelae of these adaptations. Those studies have involved rodents and calves and have focussed on growth (12) and the development of the pulmonary (13) and coronary (14) vascular beds.

We have designed a model to produce chronic hypoxemia in the newborn lamb and have studied lambs over several days of hypoxemia. We created a model of severe pulmonary stenosis with atrial septal defect. This simulates cyanotic lesions in which total pulmonary blood flow is reduced, which occurs in more than half of the infants with cyanotic heart disease (15). The degree of right ventricular outflow obstruction determines the drop in pulmonary blood flow and thus the magnitude of rightto-left atrial shunting. By varying the degree of obstruction, we could control systemic arterial $\mathrm{Hb}$ oxygen saturation precisely. We chose a saturation between 60 and $75 \%$, the usual range of saturation seen in infants with cyanotic heart disease who survive early infancy untreated: lowering saturation further would lead to an unacceptable mortality. We measured hemodynamic, hematopoietic, and growth responses to hypoxemia. This model is an accurate representation of cyanotic heart disease and can be used to define and understand how the organism adapts to chronic hypoxemia.

\section{MATERIALS AND METHODS}

Surgery. Thirteen lambs of mixed western breed aged 1 to 7 days underwent surgery. By use of local anesthesia with $0.5 \%$ lidocaine hydrochloride, polyvinyl catheters were inserted into a hindlimb artery and vein and advanced into the descending aorta and inferior vena cava. Arterial pressure and blood gases were monitored during surgery. After premedication with intravenous ketamine hydrochloride ( 5 to $8 \mathrm{mg} / \mathrm{kg}$ ) the lamb was intubated and ventilated with a Harvard respiratory pump (Harvard-Ealing Co., Millis, MA). Under isoflurane anesthesia ( 0.5 to $1.0 \%)$, and with supplemental lidocaine hydrochloride $(0.5 \%)$ locally, a left thoracotomy was performed in the fourth intercostal space. Polyvinyl catheters were advanced into the ascending aorta via the internal thoracic artery and into the superior vena cava via the internal thoracic vein. After the pericardium was opened, 
polyvinyl catheters were placed directly into the left atrium, pulmonary artery, and right ventricle. A precalibrated cuff-type electromagnetic flow transducer (C \& C Instruments, Culver City, CA) was placed loosely around the ascending aorta. A no. $5 \mathrm{~F}$ Fogarty dilation catheter (American Edwards Laboratories, Irvine, CA) was advanced from the hindlimb pedal vein until it was seen to have crossed the foramen ovale into the left atrial appendage. The balloon was then inflated with $2 \mathrm{ml}$ of $0.9 \%$ $\mathrm{NaCl}$ solution and withdrawn rapidly into the inferior vena cava, thus tearing the atrial septum. After this procedure was repeated, the catheter was removed and replaced with a polyvinyl catheter. An inflatable silicone rubber balloon with polyvinyl tubing was placed around the main pulmonary artery. The balloon was left deflated and was not constrictive. A no. $8 \mathrm{~F}$ polyvinyl tube was placed in the pleural cavity and was used as a draining chest tube for the postoperative period. All vascular catheters were filled with heparin and plugged and the chest was closed in layers. The intrathoracic catheters and cables were brought to the skin through a subcutaneous tunnel just caudal to the thoracotomy and were protected by a bag sewn to the animal's flank. The animal was then extubated and observed in a recovery area. When able to stand, the lamb was returned to its ewe and allowed to feed. Daily for the next 5 days all catheters were flushed and heparinized, the chest tube was aspirated, and antibiotics were given (1 ml of Combiotic, Henry Schein Inc., Port Washington, NY) intramuscularly. Intramuscular iron dextran complex (equivalent to $100 \mathrm{mg}$ of elemental iron) was administered weekly throughout the study, to preclude the possibility of inadequate iron stores. In the normal newborn lamb iron stores are very low (16) compared to the human (17) because of poor transplacental transfer (18), and intake or absorption also may be poor in the setting of chronic hypoxemia.

Twelve other lambs between 2 and 8 days of age underwent a similar thoracotomy. Additionally each had a microtipped manometric catheter inserted directly into the left ventricle and a piezoelectric crystal sutured to the left ventricular epicardium for measurements of myocardial performance for a different study. These animals did not undergo balloon atrial septostomies, have inflatable balloons placed around the pulmonary artery, or have pulmonary arterial or right ventricular catheters. Their postoperative period was identical and they served as control animals for the hypoxemic group.

Experimental protocol. Each animal was allowed to recover for 3 days after surgery, a period of time shown to be adequate for return of normal hemodynamic status after thoracotomy (19). On the 4th day after operation the animal was weighed and then brought to the study area, placed upright in a sling, blindfolded to minimize extraneous influences, and allowed to rest quietly under a low intensity heat lamp. Environmental temperature was maintained between 24 and $27^{\circ} \mathrm{C}$, considered within the neutral ambient temperature range for both normoxemic and hypoxemic lambs (20). All vascular catheters were flushed and connected to Statham P23Db pressure transducers (Statham Instruments, Oxnard, CA). The electromagnetic flow transducer was connected to a Statham SP2202 flowmeter (Statham Instruments). A loose-fitting bag was placed around the head to collect expired gas for continuous measurement of oxygen consumption (21). With the animal quiet, simultaneous measurements were made of aortic, pulmonary arterial, right ventricular and central venous pressure, heart rate, and ascending aortic blood flow, and were recorded on a Beckman direct writing recorder (Beckman Instruments, San Jose, CA). Immediately after the measurements, blood was obtained from the ascending aorta, coronary sinus, and pulmonary artery for measurement of hemoglobin concentration and oxygen saturation (Radiometer OSM 2 hemoximeter, Copenhagen, Denmark), blood gases (Corning 158 $\mathrm{pH}$ /blood gas analyzer, Medfield, MA), and hematocrit, and for estimation of serum protein (American Optical Corporation refractometer, Buffalo, NY). Blood oxygen content was calculated as the product of $\mathrm{Hb}$ oxygen saturation, $\mathrm{Hb}$ concentration, and a hemoglobin binding capacity of 1.36. Systemic oxygen delivery was calculated as the product of systemic blood flow and oxygen content. Extraction coefficient was calculated as the ratio of arteriovenous difference in blood oxygen content to arterial blood oxygen content. Oxygen half-saturation pressure of $\mathrm{Hb}$ (P50) was calculated from the $\mathrm{Hb}$ oxygen saturations and oxygen tensions of the three blood samples, by use of a regression analysis. In the calculation of P50, oxygen tension was not corrected for $\mathrm{pH}$ or $\mathrm{PCO}_{2}$, but was corrected for core temperature. Thus, the P50 values reflect oxygen release at the tissues, where $\mathrm{pH}$ and $\mathrm{PCO}_{2}$ fall between arterial and venous values. In the control animals we did not measure oxygen consumption, pulmonary arterial or right ventricular pressures, or pulmonary arterial or coronary sinus blood gases.

In the hypoxemia group, after the measurements were made and while pressures and flow were still being monitored, $0.9 \%$ $\mathrm{NaCl}$ was slowly infused into the circumferential pulmonary artery balloon to partially occlude that vessel. If aortic pressure or flow decreased during inflation, the balloon was quickly deflated. When right ventricular systolic pressure equalled aortic pressure we clamped the catheter and measured aortic $\mathrm{Hb}$ oxygen saturation. If saturation was less than $60 \%$, the balloon was partially deflated. If the animal was not hypoxemic despite systolic pressure in the right ventricle equalling systemic pressure, no further inflation was attempted that 1st day because of the possibility of acute right ventricular failure. Each subsequent day aortic $\mathrm{Hb}$ oxygen saturation was measured again and the balloon was inflated or deflated to obtain a saturation between 60 and $74 \%$. By the 3rd day of inflation we raised the right ventricular pressure above aortic systolic pressure if necessary. Once saturation was maintained in the range of 60 to $74 \%$ for 2 consecutive days without balloon adjustment, the balloon needed no subsequent adjustment since the saturation remained remarkably constant in each animal. For analysis purposes we considered the 1st day of hypoxemia to be that day on which full balloon inflation was achieved. This inflation procedure took between 1 and 6 days. Two animals died during it, presumably as a result of acute right ventricular failure.

In the hypoxemia group the measurements described above were repeated twice weekly in each animal. All animals were studied for at least $1 \mathrm{wk}$ of hypoxemia. The study was terminated when the animal reached $4 \mathrm{wk}$ of age. In the control group, measurements were performed only once weekly.

Analysis. Data from the hypoxemic animals were divided into subgroups according to the duration of hypoxemia on the day that the data were obtained. This method of analysis was performed because the animals became hypoxemic at different ages (range 6 to 17 days). Thus, if the data were organized according to age, animals already hypoxemic and those still normoxemic would have been analyzed together. We divided the data into six subgroups. The first subgroup of measurements was obtained the last day prior to full balloon inflation, the second between 1 and 3 days of hypoxemia, the third between 4 and 6 days of hypoxemia, the fourth between 7 and 9 days of hypoxemia, the fifth between 10 and 12 days of hypoxemia, and the sixth after 13 or more days of hypoxemia. It should be appreciated that the first group (immediately prior to full balloon inflation) does not constitute normal data because in several animals the balloon would have already been partially inflated, decreasing arterial $\mathrm{Hb}$ oxygen saturation somewhat and increasing right ventricular pressure. Not all of the animals are represented in each subgroup because measurements were obtained only twice weekly and these subgroups are split into 3-day periods, and because four animals died prior to 13 days of hypoxemia.

Data from the hypoxemia group are presented graphically in two ways. When presented without control data, they are in histogram format with each subgroup represented by a bar. When compared with control data on the same figure, it was necessary to show them by age. Each subgroup remains intact and is presented at the mean age for that group with its SD. Figure 1 
lists the mean duration of hypoxemia above each subgroup.

Statistical analyses were performed in several ways. When comparing only hypoxemia data among the different subgroups, we used analysis of variance with Newman-Keuls multiple range testing. When comparing hypoxemia data to control data over age, we performed regression analyses using the least squares approach, and compared the subsequent coefficients. When an individual group of hypoxemia data was compared to the agematched control data, unpaired $t$ tests were used. Statistical significance was considered achieved with $p<0.05$.

\section{RESULTS}

General. Eleven lambs survived the initial inflation phase of the protocol and thus were studied during hypoxemia. Of those, four died during the study period. Each of the four was found dead in its cage in the morning with no obvious cause. Autopsies showed no evidence of a myocardial or cerebral infarction, a cerebral hemorrhage, a pneumothorax, or pneumonia. The animals also were not different from the survivors with respect to systemic or pulmonary arterial Hb oxygen saturation, growth, systemic blood flow, or arterial blood gases prior to death. None of the control animals died during the study period. Prior to hypoxemia, the animals' weights and daily weight gains were normal (Figs. 1 and 2). On initiation of hypoxemia there was a dramatic drop in weight gain, which persisted throughout the study period (Fig. 2). Control animals showed a decrease in weight gain by 4 wk of age to levels approaching the hypoxemic animals.

Heart rate in the hypoxemic animals was normal at the onset of hypoxemia, but, unlike the normal decrease $(22,23)$ seen in the control animals, heart rate did not change throughout the study (Fig. 3). Aortic phasic and mean pressures and pulmonary arterial and left atrial mean pressures did not change with hypoxemia (Table 1). Right ventricular systolic pressure increased to systemic levels at full balloon inflation (Table 1). Arterial blood gases showed a mild respiratory alkalosis at the onset of

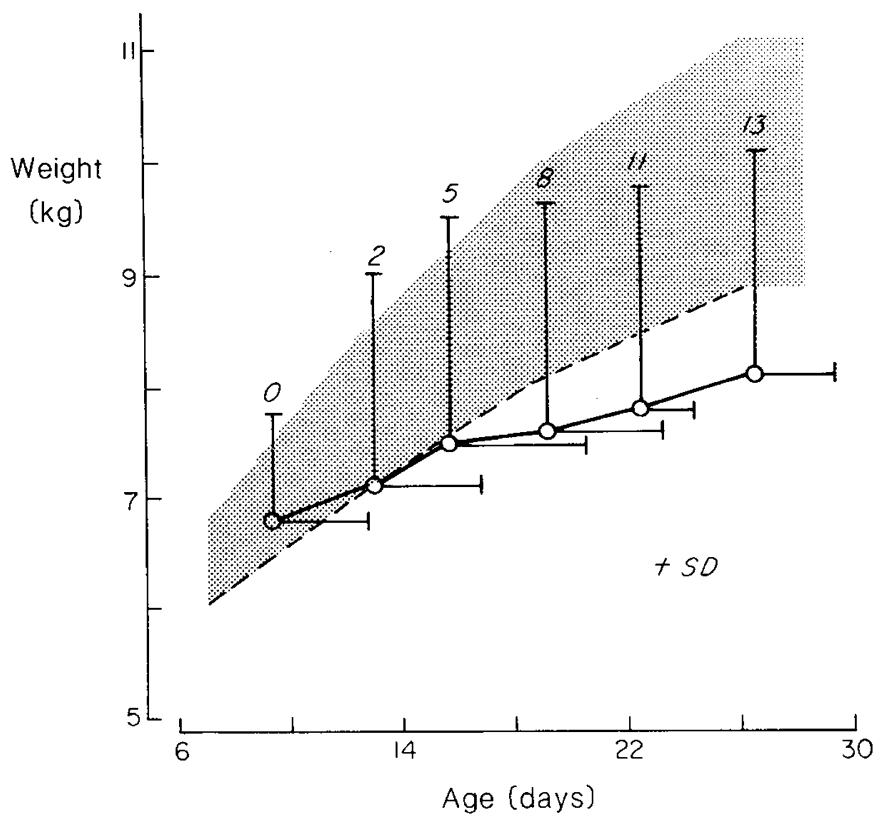

Fig. 1. Effect of chronic hypoxemia on growth. Hypoxemia data are represented by circles, with the number above each circle signifying the mean duration of hypoxemia in that subgroup. Control data are represented by a dotted line for the mean and a shaded area for 1 SD above the mean. The slope of a linear regression analysis of the hypoxemia data is significantly less steep than that of the control data, demonstrating the negative effect of chronic hypoxemia on growth.

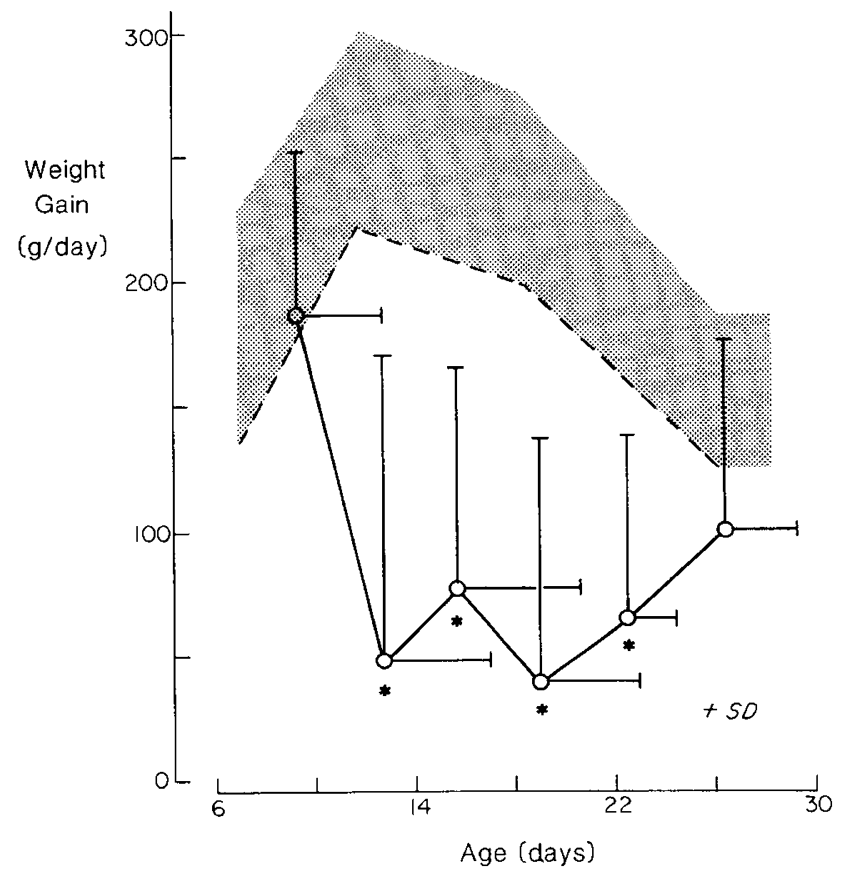

Fig. 2. Effect of chronic hypoxemia on weight gain. ${ }^{*}$ Hypoxemia data that are significantly less than age-matched control data by unpaired $t$ tests.

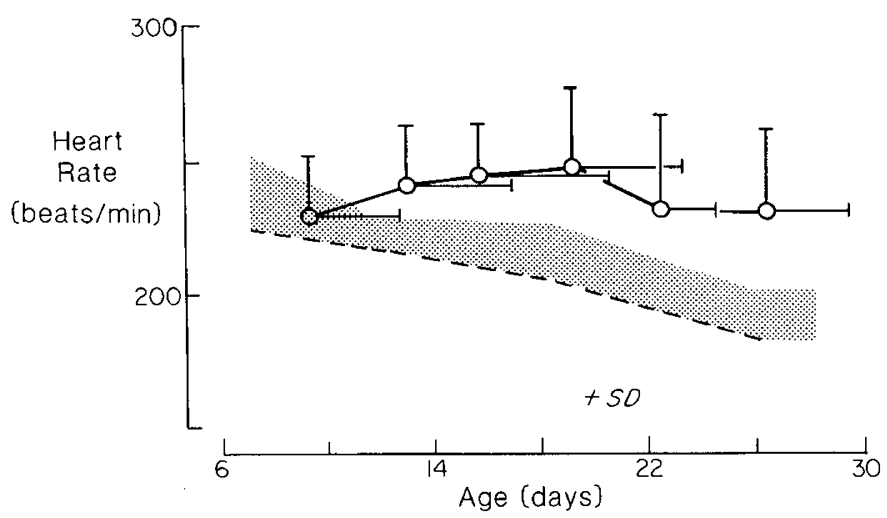

Fig. 3. Effect of chronic hypoxemia on heart rate. The slope of a linear regression analysis of the hypoxemia data is not significantly different from zero, and is more steep than the slope of the control data, indicating that heart rate remained elevated at newborn levels during chronic hypoxemia.

hypoxemia that was maintained throughout the study (Table 2). Serum protein remained constant throughout the study (Table 2).

Oxygen delivery. $\mathrm{Hb}$ concentration began to rise with full balloon inflation and continued to rise throughout the study (Fig. 4). This is in sharp contrast to normal: our control animals showed no significant change in $\mathrm{Hb}$ concentration (from $8.7 \pm$ $1.3 \mathrm{~g} / \mathrm{dl}$ at $1 \mathrm{wk}$ to $8.0 \pm 1.3 \mathrm{~g} / \mathrm{dl}$ at 4 wk of age) whereas other investigators (21) have even shown a significant decrease over this age range. Systemic arterial $\mathrm{Hb}$ oxygen saturation was slightly low prior to full balloon inflation but decreased significantly at full inflation and remained remarkably constant throughout the study (Fig. 4). Arterial oxygen content immediately dropped at full balloon inflation but the rise in $\mathrm{Hb}$ concentration throughout the study resulted in a significant increase in content after 13 days of hypoxemia (Fig. 4).

Systemic blood flow was normal prior to full balloon inflation and dropped at its onset (Fig. 5). This decrease in blood flow did not change throughout the remainder of the study. Control 
Table 1. Vascular pressures (torr) during chronic hypoxemia (mean $\pm S D$ )

\begin{tabular}{|c|c|c|c|c|c|c|}
\hline & \multicolumn{6}{|c|}{ Days hypoxemic } \\
\hline & 0 & $1-3$ & $4-6$ & $7-9$ & $10-12$ & $>12$ \\
\hline \multicolumn{7}{|c|}{ Ascending aorta } \\
\hline Diastolic & $66 \pm 8$ & $70 \pm 15$ & $69 \pm 16$ & $69 \pm 15$ & $72 \pm 10$ & $77 \pm 15$ \\
\hline Mean & $77 \pm 7$ & $79 \pm 14$ & $79 \pm 15$ & $79 \pm 16$ & $81 \pm 10$ & $88 \pm 15$ \\
\hline \multicolumn{7}{|c|}{ Right ventricle } \\
\hline Mean & $18 \pm 5$ & $16 \pm 6$ & $21 \pm 5$ & $19 \pm 6$ & & \\
\hline \multicolumn{7}{|l|}{ Left atrium } \\
\hline Mean & $3 \pm 2$ & $4 \pm 3$ & $3 \pm 3$ & $2 \pm 2$ & $5 \pm 2$ & $5 \pm 3$ \\
\hline
\end{tabular}

$*<0$ ther subgroups $(p<0.05)$

Table 2. Developmental changes in blood gases, Hb saturations, concentration and P50, and protein concentration during chronic hypoxemia (mean $\pm S D)$

\begin{tabular}{|c|c|c|c|c|c|c|}
\hline & \multicolumn{6}{|c|}{ Days hypoxemic } \\
\hline & 0 & $1-3$ & $4-6$ & $7-9$ & $10-12$ & $>12$ \\
\hline \multicolumn{7}{|l|}{ Systemic arterial } \\
\hline $\mathrm{PO}_{2}$ (torr) & $65 \pm 10^{*}$ & $43 \pm 6$ & $47 \pm 8$ & $46 \pm 6$ & $51 \pm 2$ & $46 \pm 3$ \\
\hline Saturation (\%) & $83 \pm 5^{*}$ & $62 \pm 10$ & $65 \pm 8$ & $62 \pm 10$ & $63 \pm 4$ & $61 \pm 6$ \\
\hline $\mathrm{PCO}_{2}$ (torr) & $40 \pm 5^{*}$ & $35 \pm 7$ & $34 \pm 6$ & $33 \pm 6$ & $35 \pm 8$ & $33 \pm 9$ \\
\hline $\mathrm{pH}$ & $7.40 \pm .05$ & $7.42 \pm .05$ & $7.43 \pm .04$ & $7.44 \pm .06$ & $7.44 \pm .01$ & $7.43 \pm .07$ \\
\hline \multicolumn{7}{|l|}{ Mixed venous } \\
\hline $\mathrm{PO}_{2}$ (torr) & $36 \pm 4$ & $26 \pm 5$ & $30 \pm 7$ & $28 \pm 7$ & $33 \pm 1$ & $31 \pm 3$ \\
\hline Saturation (\%) & $45 \pm 6^{*}$ & $29 \pm 10$ & $31 \pm 8$ & $30 \pm 10$ & $36 \pm 3$ & $32 \pm 7$ \\
\hline \multicolumn{7}{|l|}{ Coronary sinus } \\
\hline $\mathrm{PO}_{2}$ (torr) & $25 \pm 3$ & $16 \pm 2$ & $20 \pm 6$ & $20 \pm 5$ & $24 \pm 3$ & $24 \pm 5$ \\
\hline Saturation (\%) & $26 \pm 6$ & $14 \pm 4 \dagger$ & $19 \pm 5$ & $19 \pm 7$ & $23 \pm 1$ & $17 \pm 6$ \\
\hline \multicolumn{7}{|l|}{$\mathrm{Hb}$} \\
\hline Concentration $(\mathrm{g} / \mathrm{dl})$ & $9.4 \pm 1.5$ & $10.3 \pm 1.8$ & $10.4 \pm 1.9$ & $10.3 \pm 2.3$ & $11.4 \pm 2.1$ & $12.5 \pm 2.2^{*}$ \\
\hline P50 (torr) & $36.8 \pm 4.0$ & $38.9 \pm 5.7$ & $38.8 \pm 3.3$ & $38.8 \pm 3.7$ & $41.1 \pm 2.4$ & $39.8 \pm 1.0$ \\
\hline \multicolumn{7}{|l|}{ Protein } \\
\hline Concentration $(\mathrm{g} / \mathrm{dl})$ & $6.1 \pm 0.5$ & $6.3 \pm 0.5$ & $6.2 \pm 0.2$ & $5.9 \pm 0.3$ & $6.1 \pm 0.3$ & $6.4 \pm 0.2$ \\
\hline
\end{tabular}

$*>$ other subgroups.

$\dagger<$ other subgroups $(p<0.05)$.

animals showed a gradual decrease in systemic blood flow over the $4 \mathrm{wk}$ of study and, compared with the hypoxemic animals, there was no significant difference in flow by 18 days of age. The combined effects of the increasing $\mathrm{Hb}$, stable $\mathrm{Hb}$ oxygen saturation, and decreasing systemic blood flow on systemic oxygen delivery are shown in Fig. 5. Beyond the initial period of full balloon inflation, resting oxygen delivery was similar to control.

Oxygen utilization. Total body oxygen consumption indexed to weight dropped gradually over the $3 \mathrm{wk}$ of study in the hypoxemic lambs (Fig. 6). Prior to hypoxemia oxygen consumption was similar to that found by Lister et al. (21) at $1 \mathrm{wk}$ of age $(15.4 \pm 4.0$ versus $14.6 \pm 1.6 \mathrm{ml} \mathrm{O} 2 / \mathrm{min} / \mathrm{kg})$ and followed a similar gradual decline over the subsequent $3 \mathrm{wk}$ (to $11.6 \pm 2.0$ versus $9.8 \pm 1.8$ ). Fractional extraction of oxygen was elevated, approximately $50 \%$ (Fig. 6) as compared with 35 to $43 \%$ seen normally (21). Mixed venous and coronary sinus oxygen tensions and saturations were also low (Table 2). P50 increased during hypoxemia (Table 2), an increase similar in magnitude to that normally seen $(1,21)$.

\section{DISCUSSION}

Systemic oxygen delivery may be decreased by lowering blood $\mathrm{Hb}$ concentration, increasing $\mathrm{Hb}$ oxygen affinity, lowering inspired oxygen concentration, or decreasing systemic or effective pulmonary blood flow. Each of these changes invokes different homeostatic mechanisms to maintain oxygen delivery or decrease oxygen demand (24). The chronic adaptive mechanisms invoked in response to each change may differ significantly from the acute response. In contrast to the mature organism, the developing organism expends much of its oxygen for growth and may have quite different cardiovascular and neurohormonal responses to stress. Thus both acute and chronic responses to hypoxemia in the young organism may differ significantly from those found in the adult.

Acute hypoxemia in the young organism triggers several adaptive mechanisms to improve oxygen delivery. First, peripheral chemoreceptors detect arterial hypoxemia, and products of altered metabolism in regional beds signal tissue hypoxia. Effectors then act centrally $(25)$ and in local beds $(26 ; 27)$ to increase cardiac output and ventilation, and to direct blood from the skin, kidney, and gastrointestinal tract to the heart, brain, and adrenals (1). Increased ventilation, via pulmonary stretch receptors, further increases cardiac output and causes a marked increase in heart rate $(28,29)$. 2,3-Diphosphoglycerate produced in the red cell decreases $\mathrm{Hb}$ oxygen affinity and allows the tissues to extract more of the available oxygen (30). The sum effect of these adaptations is to maintain or increase oxygen delivery and consumption by the vital organs and decrease delivery and consumption by the nonvital organs. As long as adequate oxygen is delivered to maintain a normal oxygen consumption, decompensation does not occur.

During chronic hypoxemia many of these acute adaptations are modified. Chemoreceptor sensitivity to hypoxemia decreases, thereby abating hyperventilation and its cardiovascular sequelae (31). After the initial decrease, $\mathrm{Hb}$ oxygen affinity may return 

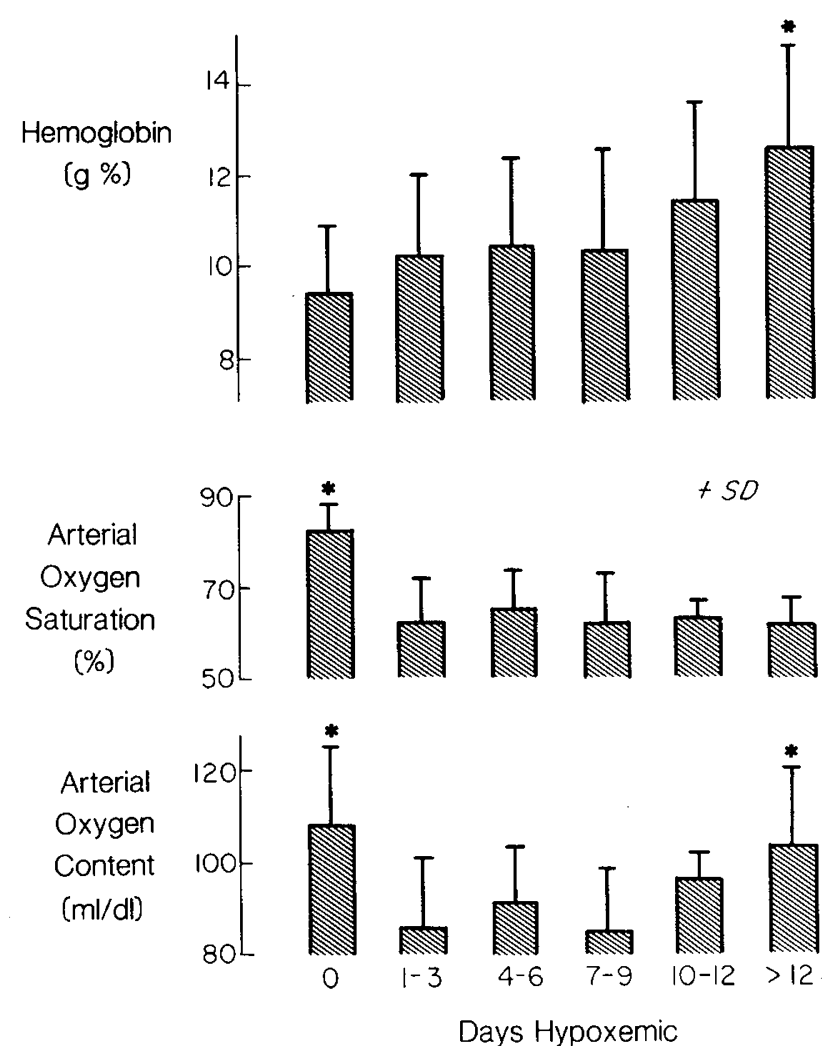

Fig. 4. Effect of chronic hypoxemia on $\mathrm{Hb}$ concentration, arterial oxygen concentration, and arterial oxygen content. *> other subgroups. $\mathrm{Hb}$ concentration increased significantly by 12 days of hypoxemia, causing a significant increase in arterial oxygen content despite no change in arterial oxygen saturation.
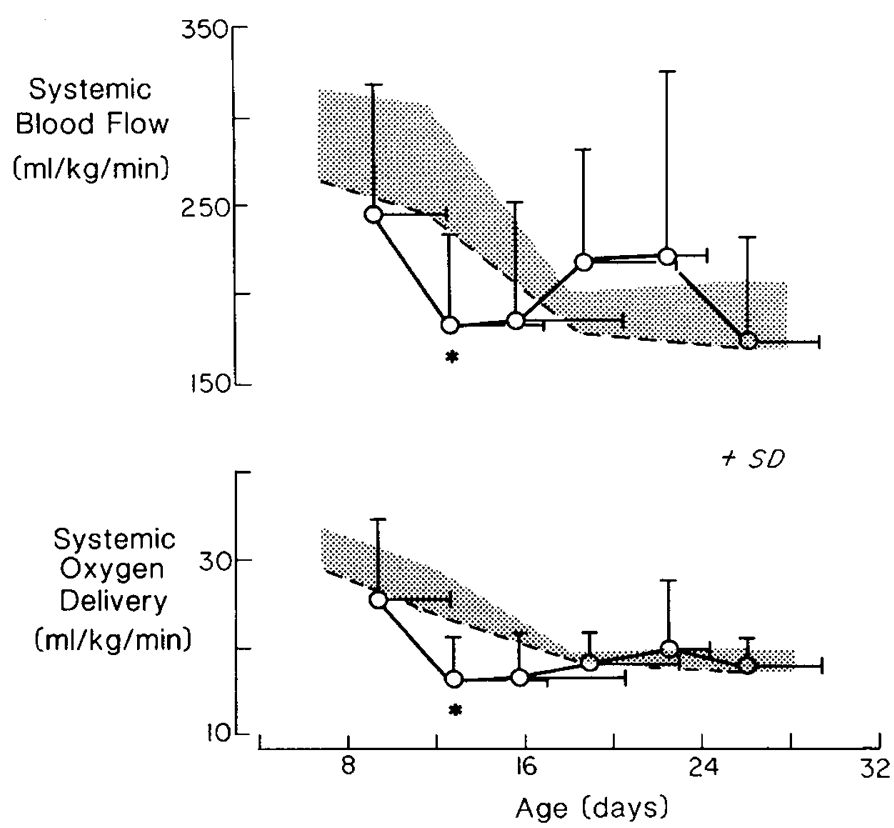

Fig. 5. Effect of chronic hypoxemia on systemic blood flow and oxygen delivery. ${ }^{*}<$ age-matched control data. Systemic blood flow decreased at balloon inflation but soon returned to control levels. There was a concomitant decrease in oxygen delivery, which then increased because of the increase in $\mathrm{Hb}$ concentration and blood flow with age.

toward normal or may remain low (32). Thus, chronic adaptive mechanisms must exist to compensate for this decreasing oxygen delivery. Metabolic activity of and regional blood flow to certain organs remain subnormal, thereby decreasing oxygen demand and thus consumption. Erythropoietin production increases total $\mathrm{Hb}$, thereby causing oxygen content in the blood to rise. These
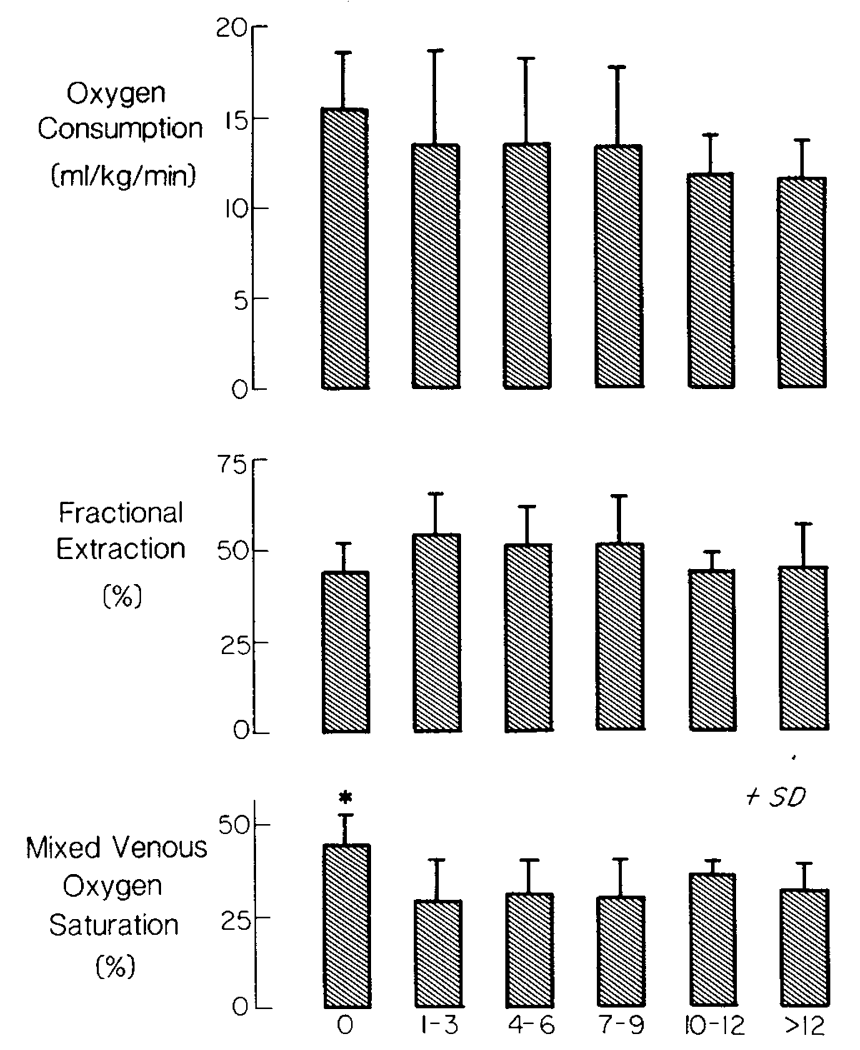

Days Hypoxemic

Fig. 6. Effect of chronic hypoxemia on oxygen utilization. *> other subgroups. Oxygen consumption followed the normal gradual decrease with increasing age (the slope of a linear regression analysis of oxygen consumption versus age was less than zero). Fractional extraction remained high and mixed venous oxygen extraction remained low during chronic hypoxemia.

chronic adaptive mechanisms may ensure survival but may cause long-term abnormalities. In the newborn, total body growth may be suppressed (33-35), brain growth and development may be subnormal (36), and polycythemia may severely alter blood flow in various vascular beds and lead to ischemia and infarction. In the newborn, chronic hypoxemia is usually caused by cyanotic heart disease. It was our purpose to create a model of cyanotic heart disease in the newborn lamb and to describe its effects on cardiovascular function, hematopoiesis, and growth.

We found that chronic hypoxemia affected the lambs in several ways. Most dramatically, growth rate decreased to approximately one-quarter of that normally seen in a 2-wk-old lamb, and remained at that level for the duration of the study. The cost to the developing organism of early growth failure cannot be overestimated. A normal newborn triples its body weight over the 1st yr of life (37), and early growth retardation cannot be completely reversed (38). More importantly, much of postnatal brain growth occurs during infancy, and inadequate growth has been associated with significant developmental delay (39). There is a large increase in the number of alveoli in the lungs (40); failure of early lung development may cause a permanently small oxygen exchange surface that will preclude the possibility of later corrective surgery. It is critical to understand the etiology of growth failure caused by chronic hypoxemia prior to embarking on a rational therapeutic course.

Growth failure in infants with cyanotic heart disease has also been documented $(33,34)$ but not well understood. Increased oxygen and substrate demand (41), abnormal hormonal status (42), inadequate caloric intake (43) or malabsorption (44), and local tissue alterations in blood flow and metabolism (35) have all been suggested as causes of failure to thrive in infants with congenital heart disease. Increased total body oxygen consumption and decreased insulin response to oral glucose $(45,46)$ have 
been described in normoxemic infants in congestive heart failure, but not in hypoxemic infants with cyanotic heart disease (41, 47). Growth hormone levels are also reportedly normal in cyanotic heart disease (48). Inadequate caloric intake has been documented in poorly growing rats made hypoxemic by decreasing inspired oxygen concentration; normoxemic animals receiving the same caloric intake also grew poorly (12). In a group of cyanotic infants, continuous enteral nutrition improved their growth (43), supporting this finding. In contrast, Naeye (35) found that factors other than undernutrition contributed to growth retardation in chronically hypoxemic mice. Blood flow may be directed away from anabolically active tissues such as muscle and bone, either through central chemoreceptor stimulation or by local alterations in oxygen or metabolite concentrations. During acute hypoxemia in 3- to 4-wk-old lambs, however, such redistribution did not occur (1). Lastly, anabolism may be suppressed directly by low intracellular oxygen tension despite adequate oxygen and substrate delivery. Tissue hypoxia is known to inhibit anabolic pathways and has been associated with decreased ATP stores (49) and DNA replication (12). Muscle growth in hypoxemic newborn rats was shown to be caused by hypertrophy rather than hyperplasia as seen in normal newborns (12). In order to assess the individual contributions of these mechanisms to growth retardation, studies must be performed on hypoxemic, normoxemic, and anemic (reduced systemic oxygen delivery with normal arterial oxygen tension) lambs in which caloric intake in controlled and gastrointestinal absorption, regional blood flow and metabolism, and hormonal status are measured.

Total body oxygen consumption indexed to weight remained normal throughout the study. The lambs were smaller than normal because of inadequate growth, so that absolute oxygen consumption was in fact lower than normal and inadequate for normal growth. An estimated $30 \%$ of oxygen consumption has been related to the newborn's metabolic requirements for growth (1). Thus a normal total body oxygen consumption in our poorly growing lambs indicates a large increase in oxygen consumption in other metabolically active areas. Myocardial oxygen consumption may have been increased. The rate-pressure product was elevated in our lambs: heart rate increased while aortic systolic pressure was maintained at normal levels, and thus left ventricular work probably increased. Right ventricular pressure was markedly elevated, thus increasing right ventricular work. Oxygen consumption of respiratory work was also probably increased. We could not measure respiratory rate as an index of work since lambs pant frequently and thus vary their respiratory rates tremendously. However, the hypoxemic animals showed intercostal retractions and nasal flaring, and hyperventilated throughout the study.

It is interesting that these lambs had a small reserve in oxygen extraction at rest. Mixed venous oxygen saturation measured at rest was significantly lower than normal, indicating that this reserve was limited. However, we observed several lambs as they shivered. From an average of about $30 \%$, mixed venous oxygen saturations decreased markedly to 15 to $20 \%$ despite no change in systemic arterial saturation and an associated increase in systemic blood flow. In association with this marked limitation in reserve was a high mortality. Four of the hypoxemic animals died during the 2-wk study, whereas all the normal animals thrived. If growth were to proceed normally in the hypoxemic lambs, the small reserve in oxygen extraction at rest would have been abolished and may have resulted in a higher mortality. We do not know why the lambs did not draw on this reserve at rest to support more normal growth. The possible mechanisms for growth retardation have been discussed previously, but whatever the dominant mechanisms, the resultant reduction in oxygen consumption may be protective or may be an associated but unrelated phenomenon.

Resting variables of cardiovascular function did not change dramatically during hypoxemia. Aortic, pulmonary arterial, and left atrial pressures were normal throughout hypoxemia. Imme- diately upon balloon inflation, cardiac output did decrease, probably as a result of acute right ventricular obstruction. Cardiac output did return to and remain at normal levels for age after 3 days of full inflation. Heart rate did not follow the normal decrease seen with increasing age, and was similar to that seen after parasympathetic biockade with atropine (8). Apparently the tachycardia resulted from release of parasympathetic tone rather than increased sympathetic drive, which should have caused an increase in cardiac output, as seen in acute hypoxemia (1). Pulmonary stretch receptors stimulated by increased respiratory effort may well have caused this persistent decrease in vagal tone (28). If the tachycardia were in fact caused by increased catecholamine production or adrenergic discharge, inotropic responsiveness to catecholamines must have been blunted, because adrenergic stimulation normally increases cardiac output as well as causing tachycardia. Blunting of adrenergic responsiveness has been described in the metabolism of brown fat under hypoxemic conditions (50). Cardiovascular responsiveness to $\alpha$ and $\beta$ adrenergic stimulation during chronic hypoxemia should be studied to fully explain these findings.

The major adaptation that we saw to normalizing systemic oxygen delivery was in the hematopoietic system. Hb concentration began to rise very early during hypoxemia and continued to rise throughout the study. The increase in $\mathrm{Hb}$ concentration to $150 \%$ of normal within 2 wk of hypoxemia caused systemic oxygen delivery to return to normal. This rise in Hb concentration is markedly different from that seen in the normal lamb. Our control animals showed no significant change in $\mathrm{Hb}$ concentration over the same time span, and other studies have even shown significant decreases (19). The difference between our control and other normal studies may be explained by the somewhat lower initial $\mathrm{Hb}$ concentration in our control animals; also, our animals received intramuscular iron injections weekly to ensure adequate iron stores. The increase in $\mathrm{Hb}$ concentration in the hypoxemic lambs may have been caused by mobilization of red blood cells from stores, a decrease in plasma volume, or erythropoiesis. Mobilization of red blood cells has not been shown to be a major adaptive mechanism in acute hypoxemia in the newborn lamb, nor has it been found to be important in chronic hypoxemia in any species. The gradual increase in $\mathrm{Hb}$ concentration in our animals strongly refutes mobilization as a major factor. Changes in plasma volume may occur in response to either acute or chronic hypoxemia. Plasma volume contraction with hemoconcentration during acute hypoxemia has been shown in some studies on humans (51) as well as rats (52). However, in other studies on humans (53) and studies on newborn lambs (54), no changes in plasma volume were demonstrated. Moreover, chronic exposure to high altitude is associated with an increase in extracellular fluid in the human (55). Although we did not measure plasma volume, the absence of changes in serum protein concentration supports the hypothesis that erythropoiesis rather than hemoconcentration was the dominant mechanism by which $\mathrm{Hb}$ concentration rose. There was no difference in the rate and magnitude of the decrease in oxygen affinity of $\mathrm{Hb}$ from that normally seen in the developing lamb. In our study absolute values higher than those previously reported (22) probably reflect differences in the method of its calculation.

In summary, in order to adapt to chronic hypoxemia, the newborn increases its $\mathrm{Hb}$ concentration to improve arterial oxygen content, persistently increases ventilation to maximize oxygen uptake, and increases heart rate to maintain cardiac output. The costs of chronic hypoxemia are a limited reserve for oxygen delivery and increased cardiorespiratory work. Together these result in high mortality and marked suppression of growth at an age when growth is critical for the full development of the organism. Many questions remain concerning the specific mechanisms that control these adaptations. Our model of stable chronic hypoxemia simulates a common form of congenital cyanotic heart disease and is ideally suited to answer such questions. 


\section{REFERENCES}

1. Sidi D, Kuipers JRG, Teitel D, Heymann MA, Rudolph AM 1983 Developmental changes in oxygenation and circulatory responses to hypoxemia in lambs. Am J Physiol 245:H674-H682

2. Stahlman M, Gray J, Young WC, Shepard FM 1967 Cardiovascular response of the neonatal lamb to hypoxia and hypercapnia. Am J Physiol 213:899904

3. Downing SE, Talner NS, Gardner TH 1966 Influences of arterial oxygen tension and $\mathrm{pH}$ on cardiac function in the newborn lamb. Am J Physiol 211:1203-1208

4. Weismann DN 1982 Tissue oxygen delivery in lambs: effect of postnatal age and acute hypoxemia. Biol Neonate 42:15-21

5. Weismann DN, Herrig JE, McWeeny OJ, Robillard JE 1983 Organ tissue blood flow responses to hypoxemia in lambs: effect of angiotensin converting enzyme inhibitor. Pediatr Res 17:195-199

6. Alexander G, Williams D 1970 Summit metabolism and cardiovascular function in young lambs during hyperoxia and hypoxia. J Physiol 208:85-97

7. Ruth V, Raivio KO 1984 Purine metabolites and lactate as parameters of hypoxia in the newborn infant. Pediatr Res 18:355-358

8. Sidi D, Kuipers J, Teitel D, Rudolph AM, Heymann M 1982 Effects of beta adrenergic blockade on response to acute hypoxemia in newborn lambs. Pediatr Res 16:117A

9. Downing SE, Gardner TH, Rocamora JM 1969 Adrenergic support of cardiac function during hypoxia in the newborn lamb. Am J Physiol 217:728-735

10. Lister G 1984 Oxygen transport in the intact hypoxic newborn lamb: acute effects of increasing P50. Pediatr Res 18:172-177

11. Urfer F-N, Bard H, Fouron J-C, Van Ameringen M-R 1983 The effect of high or low oxygen affinity red cells on tissue oxygenation and myocardial function in hypoxic newborn lambs with or without hypercapnia. Pediatr Res 17:567-572

12. Elliott DA, Cheek DB 1968 Muscle and liver cell growth in rats with hypoxia and reduced nutrition. In: Cheek DB (ed) Human Growth. Lea \& Febiger, Philadelphia, pp 326-336

13. Rabinovitch M, Gamble W, Nadas AS, Miettinen OS, Reid L 1979 Rat pulmonary circulation after chronic hypoxia: hemodynamic and structural features. Am J Physiol 236:H818-827

14. Manohar M, Parks CM, Busch MA, Tranquilli WJ, Bisgard GE, McPherron TA, Theodorakis MC 1982 Regional myocardial blood flow and coronary vascular reserve in unanesthetized young calves exposed to a simulated altitude of $3500 \mathrm{~m}$ for 8-10 weeks. Circ Res 50:714-726

15. Rowe RD, Mehrizi A 1968 The Neonate with Congenital Heart Disease. WB Saunders, Philadelphia, pp 73-82

16. Hoskins FH, Hansard SL 1964 Placental transfer and fetal tissue iron utilization in sheep. J Nutr 83:10-14

17. Widdowson EM, Spray CM 1951 Chemical development in utero. Arch Dis Child 26:205-21

18. Moodie EW 1975 Mineral metabolism. In: Blunt MH (ed) The Blood of Sheep, Composition and Function. Springer-Verlag, New York, pp 63-99

19. Sidi D, Kuipers JR, Heymann MA, Rudolph MA 1982 Recovery of cardiovascular function in newborn lambs after thoracotomy. Pediatr Res 16:705710

20. Sidi D, Kuipers JRG, Heymann MA, Rudolph AM 1983 Effects of ambient temperature on oxygen consumption and the circulation in newborn lambs at rest and during hypoxemia. Pediatr Res 17:254-258

21. Lister G, Hoffman JIE, Rudolph AM 1974 Oxygen uptake in infants and children-a simple method for measurement. Pediatrics 53:656-662

22. Lister G, Walter TK, Versmold HT, Dallman PR, Rudolph AM 1979 Oxygen delivery in lambs: cardiovascular and hematologic development. Am J Physiol 237:H668-H675

23. Klopfenstein HS, Rudolph AM 1978 Postnatal changes in the circulation and responses to volume loading in sheep. Circ Res 42:839-845

24. Ledingham IMcA 1977 Factors influencing oxygen availability. J Clin Pathol 30(suppl 11):1-6

25. Korner PI, Uther JB, White SW 1969 Central nervous integration of the circulatory and respiratory responses to arterial hypoxemia in the rabbit. Circ Res 24:757-775

26. Silver IA 1977 Local factors in tissue oxygenation. J Clin Pathol 30(suppl 11):7-13

27. Shepherd AP, Granger JH, Smith EE, Guyton AC 1973 Local control of tissue oxygen delivery and its contribution to the regulation of cardiac output. Am J Physiol 225:747-755

28. Kontos HA, Goldin D, Richardson DW, Patterson JL 1967 Contribution of pulmonary vagal reflexes to circulatory response to hypoxia. Am J Physiol 212:1441-1446

29. Kontos HA Mauck HP Jr, Richardson DW, Patterson JL 1965 Mechanism of circulatory responses to systemic hypoxia in the anesthetized dog. Am J Physiol 209:397-403

30. Sacks LM, Delivoria-Papadopoulos M 1984 Hemoglobin-oxygen interactions. Semin Perinatol 8:168-182

31. Severinghaus JW 1971 Hypoxic respiratory drive and its loss during chronic hypoxia. Clin Physiol 2:57-79

32. Edwards MJ, Novy MJ, Walters C-L, Metcalfe J 1968 Improved oxygen release: an adaptation of mature red cells to hypoxia. J Clin Invest 47:1851-1857

33. Linde LM, Dunn OJ, Schireson R, Rasof B 1967 Growth in children with congenital heart disease. J Pediatr 70:413-419

34. Gingell RL, Pieroni DR, Hornung MG 1981 Growth problems associated with congenital heart disease in infancy. In: Lebenthal E (ed) Textbook of Gastroenterology and Nutrition in Infancy. Raven Press, New York, pp 853-860

35. Naeye RL 1966 Organ and cellular development in mice growing at simulated high altitude. Lab Invest 15:700-706

36. Newburger JW, Silbert AR, Buckley LP, Fyler D 1984 Cognitive function and age at repair of transposition of the great arteries in children. $N$ Engl $\mathbf{J}$ Med 310:1495-1499

37. Hamill PVV, Drizd TA, Johnson CL, Reed RB, Roche AF, Moore WM 1979 Physical growth: National Center for Health Statistics percentiles. Am J Clin Nutr 32:607-629

38. Widdowson EM, McCance RA 1975 A review: new thoughts on growth. Pediatr Res 9:154-156

39. Evans D, Bowie MD, Hansen JDL, Modie AP, van der Spay HIJ 1980 Intellectual development and nutrition. J Pediatr 97:358-363

40. Avery ME, Fletcher BD 1974 The Lung and its Disorders in the Newborn Infant, 3rd ed. WB Saunders, Philadelphia, pp 3-21

41. Brasel JA 1968 Oxygen consumption and growth. In: Cheek DB (ed) Human Growth. Lea \& Febiger, Philadelphia, pp 474-493

42. Hait G, Corpus M, Lamarre FR, Yuan S-H, Kypson J, Chen G 1972 Alteration of glucose and insulin metabolism in congenital heart disease. Circulation 46:333-346

43. Vanderhoof JA, Hofschire PJ, Baluff MA, Guest JE, Murray ND, Pinsky WW, Kugler JD, Antonson DL 1982 Continuous enteral feedings. Am J Dis Child 136:825-827

44. Sondheimer JM, Hamilton JR 1978 Intestinal function in infants with severe congenital heart disease. J Pediatr 92:572-578

45. Stocker FP, Wilkoff W, Miettinen DS, Nadas AS 1972 Oxygen consumption in infants with heart disease. J Pediatr 80:43-51

46. Hait G, Gruskin AB, Paulsen EP 1972 Insulin suppression in children with congestive heart failure. Pediatrics 50:451-458

47. Haymond MW, Strauss AW, Arnold KJ, Bier DM 1979 Glucose homeostasis in children with severe cyanotic congenital heart disease. J Pediatr 95:220227

48. Fahrerr M, Gruneiro L, Rivarola M, Bergada C 1974 Levels of plasma growth hormone in children with congenital heart disease. Acta Endocrinol 77:451459

49. Sanders AP, Hale DM, Miller AT Jr 1965 Some effects of hypoxia on respiratory metabolism and protein synthesis in rat tissues. Am J Physiol 209:443-446

50. Heim T, Hull D 1966 The blood flow and oxygen consumption of brown adipose tissue in the newborn rabbit. J Physiol 186:42-55

51. Surks MI, Chinn KSK, Matoush LRO 1966 Alterations in body composition in man after acute exposure to high altitude. J Appl Physiol 21:1741-1746

52. Picon-Reategui E, Fryers GR, Berlin NI, Lawrence JH 1953 Effect of reducing the atmospheric pressure on body water content of rats. Am $\mathbf{J}$ Physiol 172:33-36

53. Miles DS, Bransford DR, Horvath SM 1981 Hypoxia effects on plasma volume shifts at rest, work, and recovery in supine position. J Appl Physiol 51:148153

54. Yao AC, Lu T, Castellanos R, Matanic BP 1978 Effect of prenatally and postnatally induced hypoxia on blood volume of newborn lambs. Life Sci 22:931-936

55. Picon-Reategui E, Lozano R, Valdivieso J 1961 Body composition at sea level and high altitudes. J Appl Physiol 16:580-592 